\title{
ANALISA IMPLEMENTASI FOOD WASTE MANAGEMENT DI RESTORAN ' $X$ ' SURABAYA
}

\author{
Hanjaya Siaputra ${ }^{1}$, Nadya Christianti $^{2}$, Grace Amanda $^{3}$ \\ ${ }_{1,2,3}$ Program Manajemen Perhotelan, Program Studi Manajemen, Fakultas Ekonomi, Universitas Kristen Petra \\ Jl. Siwalankerto 121-131, Surabaya, Indonesia \\ E-mail: tjunhan@petra.ac.id'; nadyach99@gmail.com²; graceamanda.97@gmail.com ${ }^{3}$
}

\begin{abstract}
Abstrak
Penelitian ini bertujuan untuk mengetahui jumlah food waste serta tahap operasional restoran yang berkontribusi paling besar dalam menghasilkan food waste. Hal ini dikarenakan melihat adanya fakta bahwa food waste dapat ditemui dimana saja dan telah menjadi masalah yang tidak dapat dihindari oleh penyedia food service. Dalam penelitian ini, objek yang digunakan peneliti adalah Restoran ' $\mathrm{X}$ ' di Surabaya dengan tipe family style restaurant. Penelitian ini menggunakan metode kualitatif dengan menggunakan teknik pengumpulan data berupa wawancara, observasi, dokumentasi serta triangulasi metode dan sumber. Hasil penelitian membuktikan bahwa food waste Restoran ' $\mathrm{X}$ ' melampaui batas normal ((41\%), yaitu sebesar 48,77\%. Tahap yang memberikan kontribusi terbesar terhadap food waste Restoran "X" adalah tahap receiving, storing, dan production.
\end{abstract}

Kata kunci: Makanan, Restoran, Limbah Makanan, Manajemen Limbah.

\begin{abstract}
The aim of this study is to determine the amount of food waste and which stage in restaurant operational that contribute the most in producing food waste. Food waste can be found anywhere and becomes a problem that cannot be avoided by food service providers. In this study, the object chosen and be analyzed by researchers is Restaurant ' $X$ ' in Surabaya which is family style restaurant. This study used qualitative method with data collection techniques such as interview, observation, documentation, also method and source triangulation. The results of this study prove that Restaurant ' $X$ 's food waste exceeds the normal limit (41\%), which is becoming $48.77 \%$. Stages that contribute the highest in producing food waste in Restaurant ' $X$ ' are receiving, storing, and production.
\end{abstract}

Keywords: Food, Restaurant, Food Waste, Waste Management

\section{PENDAHULUAN}

Food and Agriculture Organization (2017) menyatakan bahwa sepertiga makanan yang diproduksi tiap tahun yakni sebesar 1,3 miliar ton merupakan food waste. Sementara dari 7,6 miliar orang, terdapat setidaknya 815 juta orang yang kelaparan (World Hunger News, 2016). Food waste adalah makanan layak pangan yang mengalami pembuangan baik sebelum atau sesudah kadaluarsa (FAO, 2013; FAO 2017; Lipinski, 2013 dalam Linh, 2018). Di Indonesia sendiri tercatat bahwa per orang menghasilkan sebesar $300 \mathrm{~kg}$ food waste setiap tahunnya, hal inilah yang akhirnya menjadikan Indonesia sebagai negara dengan food waste terbesar kedua di dunia setelah Arab Saudi (The Economist Inteligence Unit, 2016). Berdasarkan catatan yang diberikan oleh Dinas Kebersihan dan Pertamanan dalam waktu sehari semalam, LPA Benowo dapat mengumpulkan sampah seberat 1.220,15 kg (Sulistyorini, 2006) dengan 73\% adalah sampah organic.

Dalam rangka berupaya untuk mengurangi food waste, maka peneliti tertarik untuk melakukan pene- litian yang bertujuan untuk mencari tahu bagaimana food waste di Restoran ' $\mathrm{X}$ ' di salah satu jalan utama di Surabaya untuk kemudian dapat memberikan saran yang lebih baik dalam penanganan sistem terkait food waste. Restoran ' $\mathrm{X}$ ' sendiri merupakan restoran keluarga yang berdiri sejak tahun 1980 hingga saat ini yang menyediakan menu a la carte.

Berdasarkan Food Waste Reduction Alliance (FWRA, 2014) sektor terbesar yang menghasilkan food waste adalah residential yaitu limbah yang dihasilkan oleh household (47\%). Setelah itu mengikuti dengan restoran sebesar 37\%, lalu sektor instutional sebesar $11 \%$ (contoh: rumah sakit, sekolah, dan hotel). Full-Service Restaurant sendiri memiliki empat segmentasi yaitu Family Style, Casual Dining, Upscale Dining, dan Fine Dining (chdexpert, 2018).

Penyedia food service memiliki 7 tahap operasional atau dikenal dengan Operating Control Cycle, yaitu menu planning, purchasing, receiving, storing, issuing, production, serving and service (Ninemeier, 2009). Dalam penelitian ini, ketujuh tahap operasional ini diaplikasikan ke dalam Restoran ' $\mathrm{X}$ ' yang cara penyajian makanannya dikualifikasikan sebagai 
Family Style Restaurant. Penelitian ini perlu dilakukan, karena belum pernah ada penelitian tentang food waste di restoran Family Style Restaurant. Alasan lain perlunya dilakukan penelitian di Restoran ' $\mathrm{X}$ ' adalah karena melalui hasil wawancara, ditemukan adanya indikasi tingginya food waste yang dihasilkan.

Penelitian ini dilakukan untuk mengetahui lebih lanjut mengenai food waste yang dihasilkan oleh Restoran ' $\mathrm{X}$ ' yang mengarah pada rumusan masalah pertama yaitu bagaimana pengelolaan food waste di Restoran ' $X$ '. Dilanjutkan dengan mencari pada tahapan mana di dalam 7 tahapan operasional restoran yang memberikan sumbangan terbesar atas food waste di Restoran ' $\mathrm{X}$ '

\section{LANDASAN TEORI}

Menurut FAO (2015), food waste merupakan makanan sisa yang akhirnya terbuang karena tidak dapat terkonsumsi dan atau merupakan bahan makanan yang terbuang dikarenakan adanya kelalaian ketika proses produksi, pengolahan, dan distribusi. Food waste dapat diklasifikasikan menjadi 2 macam, berdasarkan waktu dan tingkat kemungkinannya. Berdasarkan waktunya, food waste dikategorikan menjadi 3 macam (Legrand, 2017), yakni:

a. Pre-consumer waste

Didefinisikan sebagai semua trimming, spoiled food, dan produk lain dalam kitchen yang akhirnya dibuang sebelum selesai diolah menjadi menu item yang akan dikonsumsi.

b. Post-consumer waste

Sampah yang tersisa pada saat konsumen telah mengkonsumsi makanan.

c. Packaging waste and operation supplies

Terutama dalam bentuk plastik yang tidak dapat terdekomposi dengan alami. Operating supplies merupakan semua bahan yang digunakan dan menjadi waste dalam operasi food service, seperti minyak goreng dan lampu.

Sedangkan berdasarkan tingkat kemungkinan munculnya food waste, WRAP $(2009 ; 2013)$ juga mengkategorikannya menjadi 3 macam:

a. Probably avoidable waste

Makanan yang dibuang tetapi seharusnya dapat dikonsumsi apabila dikelola dengan proses yang berbeda, seperti pinggiran roti dan kulit kentang.

b. Avoidable food waste

Waste yang muncul dari adanya kelalaian manusia seperti misalnya menggosongkan suatu hidangan yang akhirnya tidak dapat dikonsumsi. Avoidable food waste dibagi menjadi 3 kategori yakni Prepared or Served in oversized quantity, not used in time, dan other. c. Unavoidable food waste

Waste dari persiapan makanan yang tidak dapat dimakan dalam keadaan normal, seperti tulang, kulit telur, kulit nanas.

Demi mendapatkan hasil yang efektif maka diperlukan adanya operating control cycle yang membagi operasional restoran menjadi beberapa tahap berdasarkan aktivitasnya (Ninemeier, 2009).

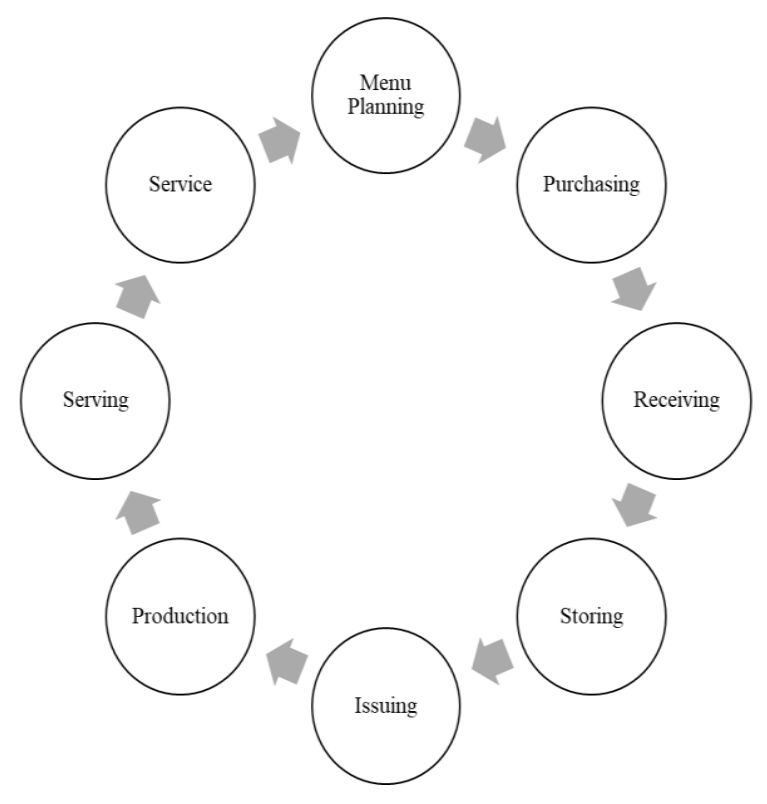

Gambar 1. Operating Control Cycle Sumber: Ninemeier, 2009

\section{Menu Planning}

Menu merupakan fondasi dalam mengontrol bisnis makanan dan minuman. Proses dari perencanaan menu itu sendiri tidak pernah selesai, dalam artian lain selalu diperlukan pembaharuan berkelanjutan (Ninemeier, 2009).

Menu memiliki dampak langsung terhadap food service operation (Ninemeier, 2009) seperti diantaranya:

\section{a. Product Control Procedure}

Produk makanan atau minuman yang hendak disajikan wajib untuk selalu dikontrol. Jika sebuah bahan makanan hendak dipakai untuk memproduksi salah satu menu item, maka dalam proses pengadaan, penyimpanan, serta penyajiannya juga harus diperhatikan dan disesuaikan oleh bahan makanan yang bersangkutan.

b. Cost Control Procedure

Suatu jenis produk makanan dan minuman yang disajikan menentukan biaya yang dikeluarkan oleh karena itu diperlukan adanya prosedur pengendalian biaya agar tidak terjadi over-costing. 


\section{c. Production Requirements}

Bahan makanan yang dibutuhkan oleh menu harus diproduksi secara konsisten seperti kualitas produk, kuantitas produk dan keterampilan karyawan semua ditentukan pula oleh jenis menu yang hendak disajikan. Kualitas yang dimaksudkan dapat berupa rasa, tekstur serta penampilan yang konsisten ketika disajikan ke setiap konsumen.

\section{Purchasing}

Purchasing merupakan salah satu aktivitas membeli bahan produksi dengan kualitas dan kuantitas pada waktu, tempat dan sumber yang tepat pula (Ninemeier, 2009). Aktivitas purchasing yang kompleks dapat dilihat pada gambar 2.3, berdasarkan gambar tersebut maka dapat dijelaskan bahwa:

1. Pada tahap awal, para koki membuat issue requisition ketika ada bahan yang diperlukan.

2. Selanjutnya, issue requisition tersebut diterima oleh storeroom, dan apabila bahan tersebut masih tersedia maka segera diberikan pada departemen bersangkutan (issues required products).

3. Namun apabila bahan yang diperlukan tersebut berada pada batas bawah/jumlah minimal bahan untuk di reorder, maka pihak storeroom akan membuat purchase requisition dan diserahkan pada purchasing department

4. Purchasing department akan memesankan bahan yang diminta ke supplier dengan menggunakan purchase order ataupun purchase record.

5. Setelah menerima purchase order, supplier akan mengirimkan bahan yang diminta ke receiving department beserta dengan deliverey invoice.

6. Pihak penerima, akan memindahkan bahan ke tempat penyimpanan yang tepat dan menyimpan delivery invoice yang telah diterima.

7. Pihak accounting akan melakukan pembayaran ke supplier sesuai dengan delivery invoice. Bukti pembayaran tersebut di duplikan agar dapat dikontrol di waktu yang akan datang.

\section{Receiving}

Hal-hal yang perlu diperhatikan dalam kegiatan penerimaan bahan (Ninemeier, 2009):

a. Memeriksa produk yang datang dengan purchase order atau purchase records.

b. Memeriksa produk yang datang dengan delivery invoices.

c. Menerima produk.

d. Memindahkan produk ke penyimpanan.

e. Mencatat dalam receiving documents.

\section{Storing}

Dalam proses penyimpanan, seringkali penyimpanan yang kurang tepat menyebabkan turunnya kualitas suatu bahan makanan, bahkan makanan yang dibekukan dalam waktu yang lama, juga akan mengurangi kualitas bahan makanan tersebut (Ninemeier, 2009). Kerugian yang timbul ini nantinya juga akan meningkatkan food cost sejumlah bahan yang disingkirkan tersebut. Untuk mengurangi kerugian akibat penyimpanan yang kurang tepat, terdapat beberapa hal yang perlu diperhatikan (Ninemeier, 2009):

a. Perputaran produk. Dengan menggunakan metode FIFO (First in first out), bahan makanan dapat bertahan lebih lama.

b. Memastikan suhu yang tepat.

c. Melakukan pembersihan rutin terhadap tempat penyimpanan bahan.

d. Memastikan setiap bahan makanan telah tersimpan dengan baik.

\section{Issuing}

Hal-hal yang perlu diperhatikan dalam kegiatan pendistribusian barang dari storage ke area produksi (Rande, 1996):

\section{a. Amounts}

Perlu adanya pencatatan atas jumlah stok yang disimpan, dan setiap kali ada bahan yang di serahkan ke departemen lain, maka jumlah stok dalam catatan juga harus dikurangi.

\section{b. Time/date}

Selain jumlahnya, waktu dan tanggal penyerahan atau pengambilan bahan juga perlu dicatat.

c. Department

Departemen dalam perusahaan juga harus mencatat bahan yang diambil dari storage, hanya orang yang berwenang yang boleh mengambil bahan dan diperlukan tanda tangannya. Pembatasan akses pengambilan bahan seperti ini dapat memudahkan manajemen untuk mengontrol.

\section{Production}

Produksi merupakan tahap kualitas produk akan mengalami pengecekan lebih lanjut untuk memastikan produk yang ditawarkan akan melebihi harapan konsumen dan menjaga agar selama proses produksi, biaya yang dikeluarkan tidak terlampau besar (Ninemeier, 2009). Berikut adalah hal-hal yang perlu diperhatikan dalam tahap production:

a. Product Quality

b. Number of Production (Purchasing)

c. Mengikuti standar operasional (resep baku dan portion size) 


\section{Service and Serving}

Serving dapat digambarkan menjadi berpindahnya suatu produk siap saji dari production staff ke pramusaji. Pada tahap ini, pramusaji melakukan kontrol terhadap kualitas produk untuk terakhir kalinya sebelum disajikan ke pelanggan. Sedangkan service menggambarkan proses penyajian dari server ke konsumen. Yang perlu diperhatikan dalam proses penyajian produk kepada konsumen (Ninemeier, 2009) diantaranya adalah:

\section{a. Timing of Service}

Konsumen yang diharuskan untuk menunggu ketika proses produksi berlangsung menjadi salah satu faktor yang mempengaruhi tingkat kepuasan konsumen terhadap layanan yang diberikan. Jika waktu menunggu konsumen terlalu lama, maka tingkat kepuasan juga akan ikut berkurang.

\section{b. Staff Communication}

Pihak produksi dan para pramusaji diwajibkan memiliki komunikasi yang baik. Hal ini untuk menghindari adanya selisih paham yang akan merugikan pihak restoran dan juga pihak konsumen.

\section{c. Adequate Supplies}

Pihak restoran wajib menyediakan backup supplies dalam jumlah yang cukup. Sebagaimana diketahui juga bahwa service, cost, dan kepuasan pelanggan sangat dipengaruhi dari ketersediaan produk di buku menu.

d. Temperature and Holding Time

Makanan yang hendak disajikan perlu diperhatikan temperaturnya.

e. Food Appearance

Penampilan makanan tidak dapat dipandang sebelah mata, makanan yang disajikan harus memiliki penampilan yang menarik. Dengan cara ini, akan mempengaruhi persepsi nilai konsumen dan meningkatkan keinginan untuk membayar sesuai harga tertera untuk produk tersebut.

\section{METODE PENELITIAN}

Penelitian ini dilakukan di Restoran ' $\mathrm{X}$ ' yang merupakan salah satu family restaurant di Surabaya. Penelitian ini merupakan penelitian kualitatif terapan (applied research). Metode kualitatif dapat memudahkan peneliiti untuk mengetahui dan mendapatkan informasi mendalam mengenai food waste di Restoran 'X'. Pengambilan data dilakukan mulai September sampai Desember 2018. Dalam menentukan informan, digunakan teknik purposive sampling. Dari teknik tersebut, dipilih 3 orang informan yaitu Pemilik Restoran, Staf pembukuan yang merangkap sebagai pramusaji, dan kepala dapur.
Dalam penelitian kualitatif ini, metode yang digunakan untuk mengumpulkan data salah satunya adalah wawancara terstruktur. Peneliti melakukan wawancara terstruktur sebanyak 4 kali, 2 kali dengan pemilik yaitu pada tanggal 11 September 2018 dan 4 Desember 2018, dengan karyawan pembukuan pada tanggal 27 November 2018, dan dengan kepala dapur pada tanggal 2018.

Selain wawancara peneliti juga melakukan behavioural observation, observasi ini dilakukan pada tanggal 12 Oktober 2018, 18 Oktober 2018 hingga 22 Oktober 2018, dan 10 Desember 2018. Peneliti memilih untuk meneliti perilaku karyawan, konsumen, ataupun pemilik serta memperhatikan kondisi yang ada di Restoran ' $\mathrm{X}$ ' yang kemudian dilihat keterkaitannya dengan food waste yang dihasilkan. Peneliti menggunakan bantuan observasi mekanik, yaitu menggunakan bantuan alat mekanik berupa kamera dan timbangan. Kamera sendiri digunakan untuk memotret situasi yang sedang terjadi dan timbangan digunakan untuk mengukur jumlah sampah yang dihasilkan Restoran ' $\mathrm{X}$ '.

Untuk menguji keabsahan data, peneliti menggunakan 2 macam metode triangulasi, yaitu triangulasi metode dan triangulasi sumber. Sebagaimana pada triangulasi metode, peneliti menggunakan observasi dan wawancara untuk menguji keabsahan data, pada triangulasi sumber, peneliti menguji keabsahan data yang diperoleh dari wawancara informan satu dengan yang lainnya. Data-data yang telah diperoleh kemudian dianalisa dengan cara menyusun, mengorganisasikan, dan memilah data sesuai dengan kategorinya untuk kemudian dapat ditarik sebuah kesimpulan dan memberikan argumentasi mengenai data tersebut.

\section{HASIL PENELITIAN DAN PEMBAHASAN}

\section{Wawancara Pemilik}

Dari hasil wawancara, terdapat beberapa hal penting yang dialami Restoran ' $\mathrm{X}$ ' diantaranya adanya hubungan yang kurang baik antar karyawan, kurang jujurnya karyawan, sering terjadi ketidaksesuaian data jumlah bahan, adanya food waste berasal dari trimming dan dari adanya bahan yang rusak akibat terlalu lama disimpan, dan Restoran ' $\mathrm{X}$ ' tidak memiliki sistem manajemen limbah.

\section{Wawancara Pembukuan}

Terdapat 4 hal yang diperhatikan oleh Informan dalam hal pembukuan diantaranya, bahan hanya akan dipesan apabila mencapai stok nol atau jumlah minimal, adanya upaya untuk menyesuaikan bahan 
yang dicatat dalam purchased order dengan bahan yang datang, adanya pencatatan jumlah dan nominal bahan yang masuk maupun yang keluar dan akan didistribusikan ke cabang, dan bahan yang telah dipesan akan disimpan dalam chiller atau freezer sesuai dengan kebutuhan bahan tersebut. Sedangkan yang paling sering terbuang dalam tahap penyimpanan adalah sayur-sayuran. Dalam tugasnya sebagai pramusaji ditemukan 2 hal, rasa dan jumlah makanan seringkali menjadi penyebab makanan terbuang pada tahap service, selain itu adanya adanya salah paham dalam makanan yang dipesan dan diproduksi juga ikut memperbesar jumlah makanan yang terbuang.

\section{Wawancara Kepala Dapur}

Berdasarkan hasil wawancara, didapatkan 6 hal yang menjadi perhatian diantaranya adalah porsi makanan yang disajikan hanya didasarkan pada perkiraan informan, food waste yang dihasilkan kebanyakan berasal dari trimming bahan yang rusak atau dari sisa produksi, food waste dapat bertambah jumlahnya karena kesalahpahaman antara pramusaji dengan asisten dapur, minyak bekas pakai yang langsung dibuang ke saluran pembuangan, tidak adanya catatan mengenai jumlah bahan dan produk yang terbuang, serta adanya pendapat informan yang mengatakan bahwa besar kecilnya jumlah food waste sangat bergantung pada kualitas bahan yang dikirimkan oleh supplier.

\section{Observasi}

Observasi meneliti beberapa hal diantaranya observasi mekanik atau mengobservasi berat sampah yang dihasilkan Restoran ' $\mathrm{X}$ ' per hari nya, melakukan observasi pada tahap menu planning, purchasing, storing, production, dan service, serta melakukan observasi data pencatatan stok bahan dan rencana pembelian yang dilakukan Restoran ' $X$ '.

Pada observasi menu planning, peneliti melihat buku menu yang dipakai di Restoran ' $\mathrm{X}$ ' pada buku menu tersebut peneliti menemukan bahwa jenis makanan yang ditawarkan oleh Restoran ' $\mathrm{X}$ ' sangat banyak. Pada observasi tahap purchasing, peneliti sempat menemukan bahwa salah satu pramusaji pergi untuk membeli beberapa bahan yang dirasa kurang untuk proses produksi hari tersebut.Dilihat dari tahap storing, peneliti melihat bahwa kondisi chiller atau freezer yang ada berada pada kondisi kotor (terdapat bercak darah yang berasal dari daging hewan dan terdapat beberapa potongan-potongan sayur yang tercecer di beberapa bagian chiller). Bahan yang disusun pun terkesan asal dan berantakan dengan beberapa bahan diantaranya disimpan pada wadah tanpa tutup, menggunakan plastik atau bahkan tetap disimpan di dalam kaleng yang sudah dibuka

Berdasarkan observasi mekanik yang dilakukan sebanyak 5 kali tersebut yakni sebesar 7,5 kg; $8 \mathrm{~kg}$; $8,1 \mathrm{~kg} ; 7,3 \mathrm{~kg} ; 7,6 \mathrm{~kg}$ atau setelah dirata-rata sekitar $7,7 \mathrm{~kg}$ per harinya dengan sampah organik yang dihasilkan berasal dari sisa produksi seperti kulit telur dan tulang, trimming sayur yang berasal dari proses persiapan produksi, serta beberapa bahan yang rusak. Sedangkan food waste yang dihasilkan oleh konsumen hanya seperti sisa acar karena sebagaimana pada observasi, peneliti menemukan seringnya konsumen membawa pulang makanan apabila terdapat sisa.

Pada observasi data pencatatan stok bahan dan rencana pembelian yang dilakukan oleh Restoran ' $\mathrm{X}$ ' mulai dari tanggal 3 Desember 2018 hingga 8 Desember 2018, pencatatan hanya dilakukan untuk bahan-bahan tertentu seperti, hiwan, kwetiau, kekian, saos tomat, udang, bihun, kecap manis, kecap asin, dan botol saos sehingga untuk bahan-bahan lainnya menjadi tidak dapat terkontrol dan hanya berdasarkan pada perkiraan kebutuhan karyawan tersebut.

\section{PEMBAHASAN}

Dari hasil observasi, ditemukan bahan yang dibeli setiap harinya rata-rata adalah $11,525 \mathrm{~kg}$. Jika dibandingkan dengan berat sampah rata-rata per hari yaitu 7,7 kg maka akan diperoleh perhitungan sebagai berikut:

a. Rata-rata sampah organik per hari

$=$ Rata-rata berat sampah/hari $\mathrm{x}$ Persentase komposisi sampah organik (73\%)

Rata-rata sampah organik per hari $=7,7 \mathrm{~kg}$ x $73 \%$ $=5,621 \mathrm{~kg}$

b. Waste percentage

= Rata-rata sampah organik/hari: Rata-rata pembelian bahan/hari

$$
\begin{aligned}
\text { Waste percentage } & =5,621 \mathrm{~kg}: 11,525 \mathrm{~kg} \\
& =48,77 \%
\end{aligned}
$$

Waste percentage adalah persen dari kehilangan produk yang disebabkan dalam cooking, trimming, portioning, atau cleaning. Dengan batas normal waste percentage yang di hasilkan oleh suatu restoran adalah 37-41\%, maka dapat dikatakan food waste yang dihasilkan Restoran ' $\mathrm{X}$ ' lebih besar dari pada angka yang seharusnya.

Pada tahap menu planning, Restoran ' $\mathrm{X}$ ' beberapa menu dapat menggunakan bahan-bahan yang serupa. Melihat perancangan menu yang sedemikian, maka dalam hal product control procedure, Restoran ' $\mathrm{X}$ ' dapat menggunakan bahan-bahannya secara efektif karena bahan yang disediakan dapat digunakan untuk beberapa menu sekaligus dan mem- 
bantu proses pengadaan bahan serta dalam hal cost dapat lebih mudah dikendalikan secara keseluruhan (mencegah over-costing) (Ninemeier, 2009).

Pada tahap purchasing, dalam menentukan jumlah bahan yang dipesan, kepala dapur dan karyawan pembukuan menggunakan perkiraan berdasarkan pengalamannya dan tidak ada perjanjian mengenai standard kualitas bahan, sehingga kualitas bahan yang dikirim terkadang baik, terkadang kurang baik. adanya pemusatan penyediaan bahan oleh Restoran ' $\mathrm{X}$ ' adalah Restoran ' $\mathrm{X}$ ' tidak mengijinkan cabangcabang dari Restoran ' $\mathrm{X}$ ' untuk memesan atau mengontak langsung supplier secara mandiri. Hal ini dikarenakan untuk mengurangi pembengkakan biaya akibat pembelian bahan yang berlebihan dan memudahkan pemilik untuk memantau aktivitas pembelian bahan yang dilakukan oleh Restoran ' $\mathrm{X}$ '.

Pada tahap receiving, Restoran ' $\mathrm{X}$ ' melakukan proses penyimpanan setelah bahan yang diterima dari supplier di bersihkan atau di trimming bagian-bagian yang rusak namun terkadang karyawan ' $\mathrm{X}$ ' lalai dalam melakukan pemeriksaan bahan yang memiliki kualitas kurang baik tetap diterima dan disimpan sehingga akhirnya menimbulkan food waste.

Pada tahap storing, Restoran ' $\mathrm{X}$ ' tidak menggunakan bantuan label berupa keterangan tanggal dan nama bahan namun lebih pada penyusunan bahan di dalam chiller dan freezer. Namun dari hasil observasi, peneliti menemukan bahwa peletakkan bahan tersebut tidak signifikan dan lebih terkesan asal diletakkan. Sedangkan penyimpanan bahan yang seharusnya dipindahkan ke wadah setelah dibuka dan diberikan keterangan tanggal yang jelas (Ninemeier, 2009) tapi oleh Restoran ' $\mathrm{X}$ ' bahan berupa makanan kaleng tidak dipindahkan ke wadah yang lain, dan walaupun ada yang dipindahkan ke wadah tidak ditutup dengan baik seperti daging-dagingan. Di Restoran ' $X$ ' juga tidak ada tanggal yang tertera, khususnya pada daging-dagingan yang disimpan dalam waktu beberapa hari sehingga cukup sulit untuk mengetahui usia bahan di dalam chiller dan freezer. Adanya inventory record yang ada pada karyawan pembukuan dan kepala dapur membantu untuk mengontrol jumlah bahan yang dimiliki oleh Restoran ' $\mathrm{X}$ ', namun terjadi ketidaksesuaian beberapa kali antara catatan yang dimiliki oleh pegawai dengan yang dimiliki oleh pemilik walaupun telah diperiksa setiap 2 minggu sekali. Alasan dari ketidaksesuaian ini adalah tidak diketahui sehingga dapat digolongkan seagai avoidable food waste dengan katagori other (WRAP, 2009; 2013).

Pada tahap issuing, bahan yang telah dipesan akan dikirim oleh supplier ke Restoran ' $\mathrm{X}$ ' yang berada dipusat, baru kemudian bahan-bahan tersebut akan didistribusikan ke cabang-cabang yang lain. Untuk proses pendistibusiannya sendiri, masingmasing perwakilan dari cabang akan mengambil bahan-bahan yang dibutuhkan di Restoran ' $\mathrm{X}$ ' yang berada dipusat, untuk bahan yang berat dan besar sendiri akan dikirim menggunakan supir. Namun yang menjadi perhatian adalah adanya bahan yang menjadi rusak ketika dalam proses pengiriman.

Pada tahap production, food waste yang dihasilkan pada tahap ini berasal dari sisa-sisa tulang, kulit telur dan juga hasil trimming sayur atau bahan yang lain yang selalu dihasilkan setiap kali operasional. Restoran ' $\mathrm{X}$ ' memiliki resep baku tetapi hanya beberapa resep yang detail seperti resep untuk saus inggris dan asam manis padahal dengan memiliki standard recipe akan lebih memudahkan perusahaan untuk mengestimasi biaya (Ninemeier, 2009). Selain itu belum ada standard portion size yang tertulis untuk beberapa menu selain menu nasi dan aneka mi sehingga lebih cenderung bergantung pada kepala dapur itu sendiri.

Pada tahap service, dalam hal timing of service di Restoran ' $\mathrm{X}$ ' dapat dikatakan singkat sehingga konsumen tidak menunggu lama dan hal ini bersangkutan dengan suhu produk yang disajikan pun tetap panas atau dingin sesuai sebagaimana harusnya makanan itu disajikan. Informan menjelaskan bahwa pernah terjadinya kesalahpahaman antara pramusaji dengan cook helper mengenai pemesanan produk dan akhirnya diganti dengan yang baru sehingga akhirnya menambah cost dan mengurangi stock yang ada. Produk yang salah produksi tersebut biasanya akan dimakan oleh karyawan atau dibuang dan tidak memiliki pencatatan secara khusus, sehingga sulit untuk diketahui jumlah porsi makanan yang dibuang atau dimakan karena adanya kesalah-pahaman.

Jika dilihat secara keseluruhan, food waste yang dihasilkan oleh Restoran ' $\mathrm{X}$ ' sebagian besar berasal dari kategori avoidable food waste yang dihasilkan sebelum proses penyajian (pre-consumer waste) (Cuglin, 2017; Legrand, 2017). Tahapan-tahapan yang menghasilkan food waste paling sering di Restoran ' $\mathrm{X}$ ' adalah receiving, storing, dan production. Hal ini dilihat berdasarkan tingkat probabilitas munculnya food waste pada ketiga tahap (receiving, storing, production) tersebut dibandingkan dengan tahapan-tahapan lainnya. Pada tahap receiving, dikatakan selalu menghasilkan food waste karena setiap kali bahan dikirimkan oleh supplier maka bahan tersebut akan di bersihkan dan akan dibuang bagianbagian yang kurang baik. Pada tahap storing, kemungkinan bahan khususnya sayur menjadi rusak juga cukup besar karena melihat kurangnya minat konsumen terhadap sayur-sayuran selain itu juga 
dipengaruhi dengan pencatatan data jumlah bahan yang dikatakan seringkali tidak sama dengan pemilik. Pada tahap production, food waste akan selalu ada karena adanya proses trimming dan pembuatan kaldu, selain itu juga dikarenakan penyajian makanannya yang selalu menggunakan perkiraan Kepala Dapur.

Food waste dikatakan hampir selalu dihasilkan pada ketiga tahap ini, berbeda dengan di tahap lain yang tidak selalu menghasilkan food waste. Pada tahap purchasing tidak ada food waste yang dihasilkan karena bahan masih di order ke supplier. Pada tahap issuing, food waste tidak selalu ada karena kejadian rusaknya bahan selama pengiriman ini tidak selalu terjadi. Pada tahap service, pada umumnya di Restoran ' $\mathrm{X}$ ' jika terdapat sisa di piring konsumen maka konsumen akan meminta untuk dibawa pulang, tapi ada pula yang ditinggal begitu saja dan akhirnya dibuang namun konsumen seperti ini dikatakan tidak banyak. Begitu pula dengan produk yang salah produksi yang dikatakan jarang terjadi.

\section{SIMPULAN DAN SARAN}

\section{Kesimpulan}

Melalui hasil wawancara serta observasi, maka dapat disimpulkan bahwa:

a. Food waste yang dihasilkan Restoran ' $\mathrm{X}$ ' berada diatas batas normal (41\%) dengan rata-rata 5,621 $\mathrm{kg}$ sampah organik per harinya atau sebesar $48,77 \%$ dari total sampah yang dihasilkan. Hal ini menjawab rumusan masalah pertama mengenai kondisi food waste di Restoran ' $\mathrm{X}$ ' yang menunjukkan food waste di Restoran ' $\mathrm{X}$ ' besar.

b. Dapat disimpukan bahwa setiap tahapan pada operating control cycle yang ada pada Restoran ' $\mathrm{X}$ ', dapat disimpulkan bahwa tahap receiving, storing dan production memiliki kontribusi terbesar dan paling sering dalam menghasilkan food waste.

c. Food waste yang dihasilkan Restoran ' $\mathrm{X}$ ' sebagian besar berasal dari proses sebelum makanan disajikan ke konsumen (pre-consumer waste) dan seharusnya merupakan food waste yang masih dapat diupayakan untuk dikurangi jumlahnya (Avoidable food waste).

\section{Saran}

Berdasarkan hasil penelitian diatas, saran yang dapat diberikan peneliti kepada Restoran ' $\mathrm{X}$ ' dalam menanggulangi food waste adalah:

a. Akibat adanya bahan-bahan makanan yang mudah rusak sebelum diberikan kepada konsumen, perlunya pencatatan berupa spoil form untuk mencatat jumlah bahan dan masakan yang dibuang atau yang tidak dapat disajikan ke konsumen sehingga akan lebih mudah melakukan pencegahan.

b. Meskipun terdapat beberapa aturan lisan mengenai takaran saji, resep serta proses pembelian dan penyimpanan bahan, namun perlu adanya Standard Operasional Procedure (SOP) tertulis yang dibuat se-detail mungkin untuk meminimalkan terjadinya kesalahan oleh pegawai. Khususnya SOP mengenai kualitas bahan yang boleh diterima/dibeli dan yang akan digunakan oleh Restoran ' $\mathrm{X}$ ', dan adanya SOP mengenai cara menyimpan bahan-bahan yang ada agar kualitas bahan yang disimpan dapat terjaga dengan baik. Menggunakan wadah yang layak dan tertutup rapat dalam menyimpan bahan-bahan serta mencantumkan label berisi nama bahan dan tanggal untuk mempermudah mengetahui usia bahan di dalam penyimpanan.

c. Dalam Restoran ' $\mathrm{X}$ ' pencatatan inventory hanya beberapa bahan seperti hiwan, kwetiau, kekian, saos tomat, udang, bihun, kecap manis, kecap asin, dan botol saos namun sebaiknya pencatatan inventory sebaiknya untuk seluruh bahan terutama daging-dagingan, makanan kaleng, beras, mi, minyak goreng, dan botol saos. Pencatatan secara detail (tanggal, jenis bahan, jumlah bahan, orang yang mengambil/mengirim bahan tersebut) dalam pengiriman atau pengambilan bahan ke cabang Restoran ' $X$ '.

d. Restoran ' $\mathrm{X}$ ' sudah memiliki beberapa resep untuk beberapa menu, namun lebih baik apabila semua resep dalam menu dicatat secara lengkap dengan takaran saji yang baku untuk menghindari porsi yang terlalu besar yang mengarah pada postconsumer waste. Adanya takaran saji yang baku untuk setiap olahan makanan.

e. Pemilik Restoran ' $\mathrm{X}$ ' memiliki masalah terkait dengan karyawan yang susah diatur maka perlu adanya sanksi yang tegas dan tertulis untuk setiap kesalahan yang dilakukan oleh pegawai agar mencegah terjadinya kesalahan yang sama.

f. Food waste yang masih memiliki nilai jual dapat di maksimalkan. Di dalam Restoran ' $\mathrm{X}$ ' dapat memaksimalkan food waste dengan cara memisahkan sampah organik dan anorganik, sehingga sampah organik dapat diolah untuk dikompos, selain itu minyak bekas yang sudah tidak digunakan juga dapat dijual.

\section{DAFTAR REFERENSI}

Chdexpert. (2018). Full service restaurant data. Retrieved on September 23, 2018 fromhttps:// www.chd-expert.com/products/foodservicedata/ databases/commercial/full-service-restaurant/ 
Cuglin, A.M., Petljak, K. \& Naletina, D. (2017). Exploratory research of food waste generation and food waste prevention in the hospitality industry: The case of Zagreb restaurants. Retrieved on September 3 from https://www. researchgate.net/publication/324411983_Explor atory_research_on_food_waste_generation_and _food_wate_prevention_in_the_hospitality_indu stry_-_the_case_of_Zagreb_restaurants

FAO. (2013). Food Wastage Footprint Impacts on Natural Resources: Summary Report.Retrieved on September 3 from http://www.fao.org/ docrep/018/i3347e/i3347e.pdf

FAO. (2015). Save food: Global initiative on food loss and waste reduction. Retrieved on September 4 from http://www.fao.org/3/a-i4068e.pdf

FAO. (2017). Key facts on food loss and waste you should know! Retrieved on September 4, 2018 fromhttp://www.fao.org/save-food/resources/ keyfindings/en/

Food Waste Reduction Alliance. (2014). Analysis of U.S. food waste among food manufactures, retailers, and restaurants. Retrieved on September 7 from https://www.foodwastealliance.org/wpcontent/uploads/2014/11/FWRA_BSR_Tier3_F INAL.pdf

Legrand, W., Sloan, P. \& Chen, J.S. (2017). Sustaiability in the hospitality industry ( ${ }^{\text {rd }}$ ed.). London: Routledge

Linh, N. K. (2018). Food waste management in the hospitality industry. Retrieved on November 12, 2018 fromhttps://www.theseus.fi/bitstream/handle/10024/142528/NGUYEN_KHANH\%20LI NH.pdf?sequence $=1$
Ninemeier, J.D. (2009). Planning and control for food and beverage operations. Michigan: American Hotel \& Lodging Educational Institute.

Rande, W. L. (1996). Introduction to professional foodservice. New York: John Wiley \& Sons, Inc.

Sulistyorini, L. (2006). Volume sampah di kota Surabaya.Retrieved on September 6, 2018 from https://www.scribd.com/document/363067572/3 970-ID-volume-sampah-di-kota-surabaya-pdf

The Inteligence Unit. (2016). Food loss and food waste. Retrieved on September 4, 2018 from http://perspectives.eiu.com/sustainability/foodsustainability-index-2016/infographic/food-lossand-waste

World Hunger News. (2016).2018 World hunger and poverty facts and statistics. Retrieved on September 4, 2018 from https://www.world hunger.org/world-hunger-and-poverty-facts-andstatistics/\#hunger-number

WRAP. (2009). Household food and drink waste in the UK. Retrieved on September 23, 2018 fromhttp://www.wrap.org.uk/sites/files/wrap/Ho usehold_food_and_drink_waste_in_the_UK_report.pdf

WRAP. (2013). The true cost of food waste within hospitality and food service: Final report. Retrieved September 23, 2018 from http://www. wrap.org.uk/sites/files/wrap/The\%20True\%20C ost $\% 20$ of $\% 20$ Food $\% 20$ Waste $\% 20$ within $\% 20 \mathrm{H}$ ospitality\%20and\%20Food\%20Service\%20Sect or\%20FINAL.pdf 